\title{
Hepatic iron accumulation in copper-deficient rats
}

\author{
BY DARRYL M. WILLIAMS, F. SCOTT KENNEDY AND BRENDA G. \\ GREEN \\ Departments of Internal Medicine and Biochemistry, Louisiana State University Medical \\ Center in Shreveport, PO Box 33932, Shreveport, Louisiana 71130-3932, USA
}

(Received 9 March 1983 - Accepted 7 June 1983)

\begin{abstract}
1. Studies of anaemia and tissue iron distribution were carried out in copper-deficient rats and pair-fed control animals given $\mathrm{Fe}$ orally or parenterally in varying doses.

2. The anaemia of $\mathrm{Cu}$ deficiency was partially but incompletely corrected by oral Fe supplementation of oneto five-fold normal dietary levels or by intramuscular Fe supplementation.

3. Serum $\mathrm{Fe}$ increased in $\mathrm{Cu}$-deficient animals as the dose of supplemental Fe was increased.

4. Hepatic Fe accumulation occurred in $\mathrm{Cu}$-deficient rats which were administered with either oral $\mathrm{Fe}$ in twoto five-fold excess or low doses of intramuscular $\mathrm{Fe}$. This difference was not seen in animals receiving high doses of intramuscular $\mathrm{Fe}$, but similar relative differences were seen in $\mathrm{Cu}$-deficient and $\mathrm{Cu}$-replete rats which had been given no Fe supplementation.

5. Duodenal $\mathrm{Fe}$ was not increased in $\mathrm{Cu}$ deficiency. Bone marrow Fe was present in $\mathrm{Cu}$-deficient animals receiving either parenteral or oral $\mathrm{Fe}$ supplementation.

6. Present studies suggest that a decrease in caeruloplasmin $(E C 1.16 .3 .1)$ activity does not wholly explain the anaemia of $\mathrm{Cu}$ deficiency. Fe accumulation may be restricted to the liver, suggesting that $\mathrm{Cu}$ may be required for normal intracellular Fe metabolism.
\end{abstract}

Copper deficiency results in microcytic hypochromic anaemia in association with impaired iron utilization even when adequate $\mathrm{Fe}$ is provided by parenteral administration (Lee et al. 1976). Such findings have provided the basis for the concept that $\mathrm{Cu}$ is required for the normal movement of $\mathrm{Fe}$. In swine, evidence has been presented that gastrointestinal mucosal $\mathrm{Fe}$ absorption, hepatic $\mathrm{Fe}$ release and reticuloendothelial $\mathrm{Fe}$ release are impaired and that all these factors contribute to the anaemia and abnormal Fe distribution (Lee $e t$ al. 1968). A unifying hypothesis has been sought to explain these abnormalities. The prevailing explanation holds that defective $\mathrm{Fe}$ release from these various sites results from reduced levels of the plasma cuproprotein, caeruloplasmin. This protein is a potent ferroxidase. Presumably, caeruloplasmin acts at cell surfaces to oxidize Fe so that ferric iron can be bound to the transport protein, transferrin (Roeser et al. 1970).

However, there is evidence which suggests that this hypothesis may not completely explain the abnormalities of $\mathrm{Fe}$ metabolism which are seen in $\mathrm{Cu}$ deficiency. This evidence includes the observations: (1) that there is a defect of Fe metabolism within the Cu-deficient reticulocyte (Williams et al. 1976) and (2) that Fe administered intraperitoneally can be identified in the bone marrow of Cu-deficient rats (Marston et al. 1971). Recent studies have shown that when $\mathrm{Fe}$ is supplied in two- to four-fold excess to $\mathrm{Cu}$-deficient rats, anaemia may be prevented (Weisenberg et al. 1980). These studies are in contrast to numerous earlier publications which have shown that Fe replacement at conventional doses will only partially alleviate the anaemia of $\mathrm{Cu}$ deficiency.

The purpose of this report was to describe the influence of the route and dosage of $\mathrm{Fe}$ administration on the anaemia of $\mathrm{Cu}$ deficiency in rats and to determine the nature of tissue $\mathrm{Fe}$ distribution in these animals. 


\section{MATERIALS AND METHODS}

\section{Animals and diet}

Male Sprague-Dawley rats were weaned at $21 \mathrm{~d}$ of age and paired, by weight, to within $0.5 \mathrm{~g}$. Rats were placed in individual hanging stainless-steel cages and fed by matched-pair technique with a diet of unsupplemented condensed milk. This diet has previously been used in a series of studies extending back over 30 years (Chase et al. 1952; Williams et al. 1974,

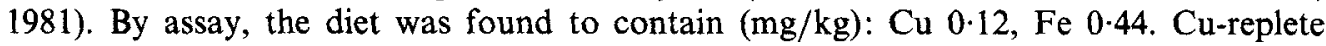
animals received $1.0 \mathrm{mg} \mathrm{Cu} / \mathrm{d}$ in the form of copper sulphate added to the diet. Animals were weighed weekly during the course of the experiments. In all experiments, weight gain of matched pairs was similar until the last 2 weeks of the experiment when $\mathrm{Cu}$-deficient animals failed to keep up with matched pair-fed, Cu-replete animals. Growth curves were comparable to those reported by others (Mills \& Murray, 1960). Control rats were fed ad lib. from weaning on a commercial diet (Ralston-Purina) which was found by analysis to contain $(\mathrm{mg} / \mathrm{kg})$ : $\mathrm{Cu} 10 \cdot 7, \mathrm{Fe} 300$.

\section{Fe supplementation}

In some experiments, rats received parenteral $\mathrm{Fe}$ as iron dextran (Imferon; Merrill, $50 \mathrm{mg}$ $\mathrm{Fe} / \mathrm{ml}$ ) given intramuscularly (IM) in a daily dose of $5 \mathrm{mg} \mathrm{Fe}$ with a total dose of $0,5,10$, 25 or $50 \mathrm{mg}$. In other experiments, rats received oral Fe supplementation in the form of ferrous ammonium sulphate added to the experimental diet in the final concentrations of 100,200 and $500 \mathrm{mg} \mathrm{Fe} / \mathrm{kg}$. These levels approximated to one, two and five times the levels of Fe recommended in other synthetic diets (Mills \& Murray, 1960).

\section{Analytical methods}

After 6 weeks on the experimental diet, animals were anaesthetized by carbon dioxide narcosis and killed by exsanguination from the inferior vena cava. Haemoglobin, packed cell volume and erythrocyte counts were determined by automated methods (Pinkerton $e t$ al. 1970). Bone marrow samples were obtained from the femoral shaft, stained for $\mathrm{Fe}$ by the Prussian blue reaction (Cartwright, 1968), examined for Fe by a single observer without knowledge of the sample source, and scored 0 to $4+$ for the presence of reticuloendothelial $\mathrm{Fe}$ stores. Other tissues were harvested, rinsed in saline ( $9 \mathrm{~g}$ sodium chloride $/ 1)$, blotted dry and weighed.

Serum $\mathrm{Fe}$ and $\mathrm{Cu}$ were measured by previously published methods and tissue $\mathrm{Fe}$ and $\mathrm{Cu}$ were measured by atomic absorption spectroscopy following acid digestion (Williams et al. 1976). Caeruloplasmin (EC 1.16.3.1) was measured by its capacity to oxidize $p$-phenylenediamine ( $p$ PD; Ravin, 1961).

\section{RESULTS}

\section{Effect of Fe supplementation}

In animals receiving no $\mathrm{Fe}$ supplementation, haemoglobin levels were decreased in both $\mathrm{Cu}$-replete and $\mathrm{Cu}$-deficient animals (Table 1). The mean level of haemoglobin was less in $\mathrm{Cu}$-deficient than in the $\mathrm{Cu}$-replete groups. When $\mathrm{Fe}$ supplementation was provided either orally or parenterally at levels estimated to be near basal requirement, haemoglobin levels of $\mathrm{Cu}$-replete animals were similar to those of animals receiving the commercial diet. Haemoglobin levels of $\mathrm{Cu}$-deficient animals remained significantly lower than those of controls given the commercial diet, but were greater than those of $\mathrm{Cu}$-replete animals which received no Fe supplementation.

Microcytosis was a feature in both groups receiving no Fe supplementation. Erythrocyte size increased with either oral or parenteral $\mathrm{Fe}$ supplementation, but the cells remained 


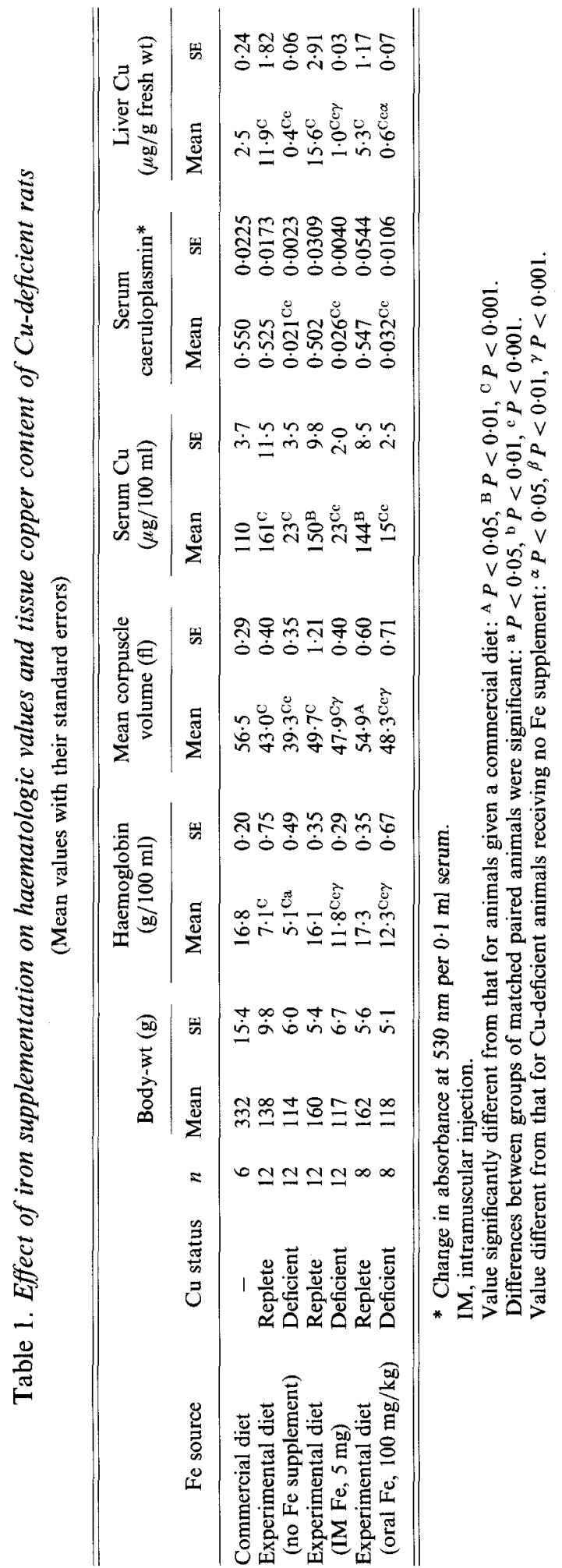


statistically significantly smaller than those of control animals, and the cells of Cu-deficient animals were smaller than those of their $\mathrm{Cu}$-replete counterparts.

The serum $\mathrm{Cu}$ levels of all $\mathrm{Cu}$-replete animals were significantly higher than those of animals given a commercial diet, while levels in $\mathrm{Cu}$-deficient groups were decreased. However, serum caeruloplasmin of each of the $\mathrm{Cu}$-replete groups was not appreciably different from control animals receiving commercial diets. In $\mathrm{Cu}$-deficient animals caeruloplasmin activity, using $p \mathrm{PD}$ as substrate, was $4.0,5.2$ and $5.9 \%$ of respective values in matched counterparts in groups receiving no Fe supplementation, parenteral Fe supplementation and oral $\mathrm{Fe}$ supplementation. Liver $\mathrm{Cu}$ content reflected the status of $\mathrm{Cu}$ repletion.

Serum $\mathrm{Fe}$ was significantly decreased in all animals receiving no $\mathrm{Fe}$ supplement, regardless of $\mathrm{Cu}$ status (Table 2). In other experimental groups, the serum $\mathrm{Fe}$ was lower in $\mathrm{Cu}$-deficient rats than in either $\mathrm{Cu}$-replete counterparts or control animals given the commercial diet.

Bone marrow Fe was absent by histochemical analysis in rats receiving no Fe supplementation, but in other groups, regardless of the route of Fe supplementation, bone marrow Fe stores were greater in experimental animals than in control rats given a commercial diet. In animals receiving oral $\mathrm{Fe}$ supplementation, bone marrow $\mathrm{Fe}$ was significantly greater in $\mathrm{Cu}$-replete than in $\mathrm{Cu}$-deficient animals.

Liver $\mathrm{Fe}$ concentration was consistently greater in $\mathrm{Cu}$-deficient than in $\mathrm{Cu}$-replete counterparts, regardless of the route of Fe supplementation. Splenic iron was greater in $\mathrm{Cu}$-deficient animals only when $\mathrm{Fe}$ was administered parenterally. Kidney $\mathrm{Fe}$ was greater in $\mathrm{Cu}$-deficient animals when there was no $\mathrm{Fe}$ supplementation of the diet.

\section{Effect of varying dose of oral Fe}

In these experiments (Table 3), the experimental diet was supplemented with Fe at two or five times $(200$ and $500 \mathrm{mg} / \mathrm{kg})$ the level in the previous study $(100 \mathrm{mg} / \mathrm{kg})$. In both treatment groups, haemoglobin levels of $\mathrm{Cu}$-replete animals were similar to those observed previously in rats given a commercial diet, but haemoglobin levels in $\mathrm{Cu}$-deficient animals were significantly decreased. At both dosages of Fe the level of haemoglobin in both $\mathrm{Cu}$-deficient and $\mathrm{Cu}$-replete rats was higher than had been observed in animals receiving no Fe supplement.

At both dosages of $\mathrm{Fe}$, serum $\mathrm{Cu}$ levels were decreased in $\mathrm{Cu}$-deficient animals and serum $\mathrm{Fe}$ was significantly lower in $\mathrm{Cu}$-deficient groups. Serum $\mathrm{Fe}$ in $\mathrm{Cu}$-deficient animals increased with increasing Fe dose so that at an oral Fe dosage level of $500 \mathrm{mg} / \mathrm{kg} \mathrm{Fe}$, serum $\mathrm{Fe}$ in $\mathrm{Cu}$-deficient animals was $79 \%$ of that observed in rats given a commercial diet. Even at that level of serum $\mathrm{Fe}$, haemoglobin levels of $\mathrm{Cu}$-deficient animals were significantly less than in matched groups.

Liver iron was significantly increased in $\mathrm{Cu}$-deficient rats compared with their matched controls at both levels of Fe supplementation while spleen and kidney Fe were significantly decreased. No difference was observed in cardiac Fe.

\section{Effect of varying dose of parenteral Fe}

In these studies (Table 4), both $\mathrm{Cu}$-deficient and $\mathrm{Cu}$-replete rats were given graduated doses of iron dextran by intramuscular injection. Increasing Fe supplementation again resulted in incomplete correction of anaemia in $\mathrm{Cu}$-deficient animals. Indeed, as the dosage of $\mathrm{Fe}$ was increased, increased mortality was observed, and there was a progressive decline of haemoglobin levels in $\mathrm{Cu}$-replete animals. Serum $\mathrm{Cu}$ levels were significantly decreased in $\mathrm{Cu}$-deficient animals of each study group but, as serum $\mathrm{Fe}$ increased with increased $\mathrm{Fe}$ dosages, anaemia remained uncorrected in the $\mathrm{Cu}$-deficient rats. Liver Fe was significantly 

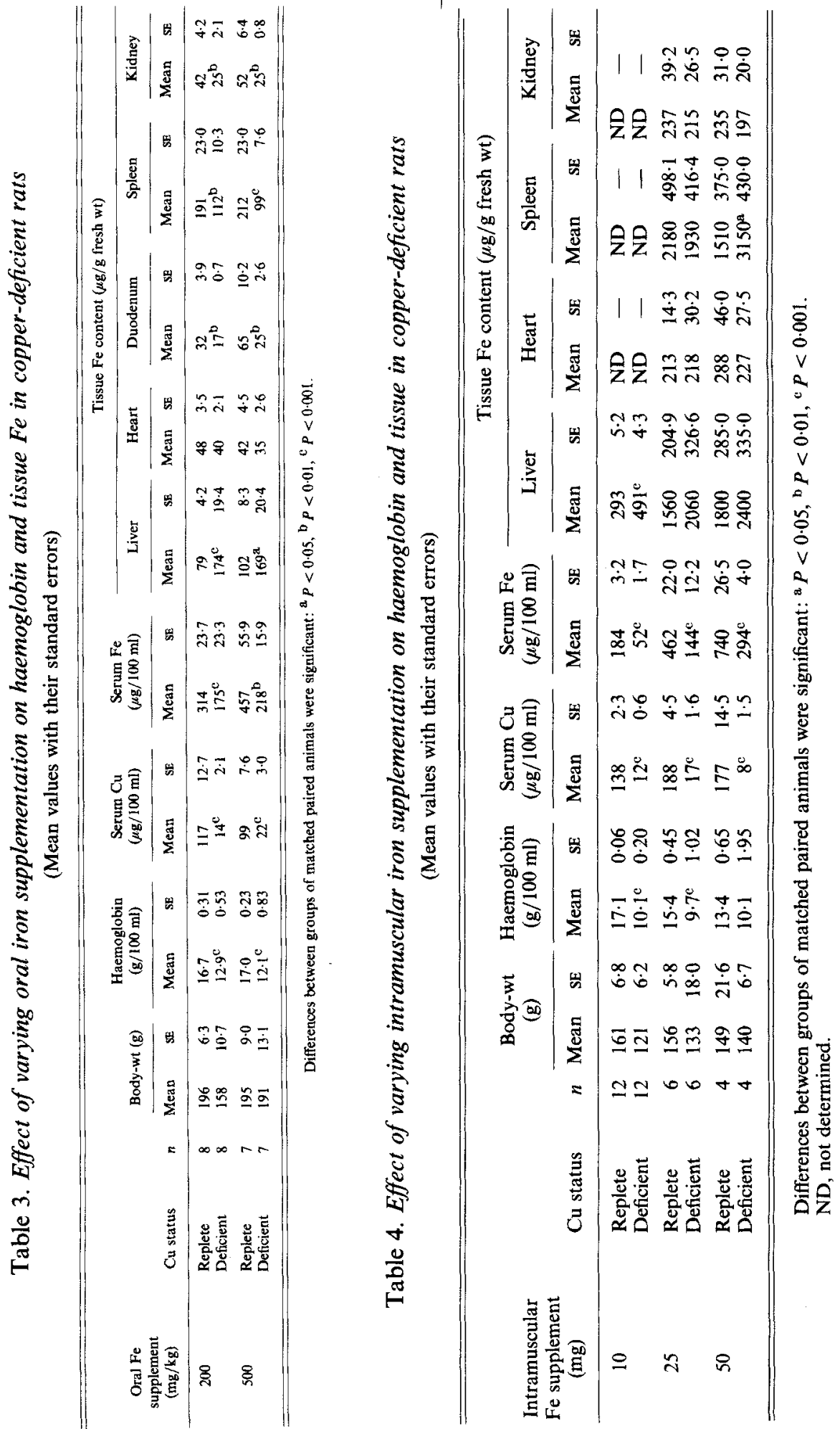
increased in $\mathrm{Cu}$-deficient animals only at a level of $\mathrm{Fe}$ supplementation of $10 \mathrm{mg} \mathrm{Fe}$. At higher doses of $\mathrm{Fe}$, mean liver $\mathrm{Fe}$ was higher in $\mathrm{Cu}$-deficient animals, but considerable variability was observed so that no significant difference was observed between groups of animals. Unfortunately, Fe concentrations of other organs were not measured in animals receiving $10 \mathrm{mg} \mathrm{Fe}$, but splenic $\mathrm{Fe}$ was significantly increased in $\mathrm{Cu}$-deficient animals receiving $50 \mathrm{mg} \mathrm{Fe}$.

\section{DISCUSSION}

The results of this study show that under the reported experimental conditions, anaemia persisted in $\mathrm{Cu}$-deficient rats regardless of the $\mathrm{Fe}$ dose or route of administration. Thus, even when oral $\mathrm{Fe}$ intake was increased five-fold, the haemoglobin level in $\mathrm{Cu}$-deficient animals was less than that of Cu-replete animals but greater than that of Fe-deficient, $\mathrm{Cu}$-deficient animals. These observations are at odds with recent reports that oral $\mathrm{Fe}$ given in two- to four-fold excess to $\mathrm{Cu}$-deficient rats results in the alleviation of anaemia (Weisenberg et al. 1980). The source of this discrepancy is unclear, but Fe doses used in our study were likely to be as great as those in the report by Weisenberg et al. (1980). Direct comparisons are difficult because, in that report, animals received a solid diet containing $40-80 \mathrm{mg} \mathrm{Fe} / \mathrm{kg}$ supplemented with drinking water containing $20 \mathrm{mg} / \mathrm{l}$. The techniques of metal determinations are also different, but the relative extent of $\mathrm{Cu}$ deficiency and, in some experiments, Fe deficiency appear to be similar.

Our findings are similar to numerous earlier reports which showed that Fe supplementation incompletely corrected the anaemia of Cu deficiency (Smith \& Medlicott, 1944; Roeser et al. 1970; Lee et al. 1968, 1976). We also observed that Fe accumulated in the livers of all $\mathrm{Cu}$-deficient animals, regardless of dosage or route of Fe supplementation. Such an increase was not observed by Weisenberg et al. (1980), but similar elevations have been seen in Cu-deficient rats (Evans \& Abraham, 1973; Owen, 1973) and swine (Lee et al. 1968, 1976; Roeser et al. 1970) receiving Fe orally or parenterally. It has been proposed that this hepatic $\mathrm{Fe}$ accumulation is due to deficiency of caeruloplasmin which catalyzes the release of $\mathrm{Fe}$ from the isolated, perfused liver (Osaki \& Johnson, 1969). Recent studies have suggested that under conditions which simulate physiologic oxygen tension, caeruloplasmin may not be required for hepatic Fe release (Baker et al. 1980). Other blood-borne substances have also been shown to possess ferroxidase activity (Lee et al. 1969; Topham et al. 1980; Prohaska, 1981) raising still further objections to the caeruloplasmin ferroxidase hypothesis. The absence of anaemia or evidence of impaired Fe metabolism in Wilson's disease (O'Reilly et al. 1968) or Menkes' syndrome (Danks et al. 1972) pose additional questions about the role of $\mathrm{Cu}$ and of caeruloplasmin in Fe metabolism.

In the studies which we report, the pattern of Fe accumulation in other Fe storage organs does not parallel that seen in the liver. The spleen and bone marrow are major sources of Fe for erythroid haem synthesis (Jacobs \& Worwood, 1978). However, in Cu-deficient animals receiving oral $\mathrm{Fe}$ supplementation, splenic and marrow $\mathrm{Fe}$ are both less than in $\mathrm{Cu}$-replete animals while liver $\mathrm{Fe}$ is greater. If $\mathrm{Fe}$ metabolism in these tissues were dependent upon caeruloplasmin, it would be anticipated that the Fe content in these tissues, like the liver, would be increased. If, on the other hand, the reduced Fe content would be attributed to decreased mucosal absorption of $\mathrm{Fe}$, then $\mathrm{Fe}$ accumulation within the liver should also be decreased. Our studies do not permit a direct comment on the nature of $\mathrm{Fe}$ absorption in $\mathrm{Cu}$-deficient rats. We observed that duodenal $\mathrm{Fe}$ content of $\mathrm{Cu}$-deficient animals was less than that of $\mathrm{Cu}$-replete controls, but Lee et al. (1968) have shown that Fe accumulates in the mucosa and submucosa of $\mathrm{Cu}$-deficient swine. We did not attempt to identify such microscopic mucosal and submucosal Fe accumulation.

Previous studies from our laboratory have shown that intracellular Fe metabolism and 
haem synthesis is impaired in Cu-deficient reticulocytes (Williams et al. 1976) and that haem catabolism may be accelerated in Cu-deficient hepatocytes (Williams et al. 1981). Either mechanism may contribute to hepatic Fe accumulation without invoking the caeruloplasmin ferroxidase hypothesis. Further investigation of hepatic Fe accumulation may provide greater insight into the defect of $\mathrm{Fe}$ metabolism associated with $\mathrm{Cu}$ deficiency.

The authors are grateful to Mrs Ann Chatelain for her assistance in the preparation of the manuscript. This work was supported in part by a grant, AM 23004, from the National Institute of Health, Bethesda, Maryland, USA.

\section{REFERENCES}

Baker, E., Morton, A. G. \& Tavill, A. S. (1980). British Journal of Haematology 45, 607-620.

Cartwright, G. E. (1968). Diagnostic Laboratory Hematology, 4th ed. New York: Grune \& Stratton.

Cartwright, G. E. \& Lee, G. R. (1971). British Journal of Haematology 21, 147-152.

Chase, M. S., Gubler, C. J., Cartwright, G. E. \& Wintrobe, M. M. (1952). Journal of Biological Chemistry 199, $757-763$.

Danks, D. M., Campbell, P. E., Stevens, B. J., Mayne, V. \& Cartwright, E. (1972). Pediatrics 50, $188-201$.

Evans, J. L. \& Abraham, P. A. (1973). Journal of Nutrition 103, 196-201.

Jacobs, A. \& Worwood, M. (1978). In Metals and the Liver, pp. 3-51 [L. W. Powell, editor]. New York: Marcel Dekker.

Lee, G. R., Nacht, S., Christensen, D., Hansen, S. P. \& Cartwright, G. E. (1969). Proceedings of the Society for Experimental Biology and Medicine 131, 918-923.

Lee, G. R., Nacht, S., Lukens, J. N. \& Cartwright, G. E. (1968). Journal of Clinical Investigation 47, $2058-2069$.

Lee, G. R., Williams, D. M. \& Cartwright, G. E. (1976). In Trace Elements in Human Health and Disease vol. 1 Zinc and Copper, pp. 373-393. [A. S. Prasad and D. Oberleas, editors]. New York: Academic Press.

Marston, H. R., Allen, S. H. \& Swaby, S. L. (1971). British Journal of Nutrition 25, 15-30.

Mills, C. F. \& Murray, G. (1960). Journal of the Science of Food and Agriculture 11, 547-552.

O'Reilly, S., Pollycove, M. \& Bank, W. J. (1968). Neurology 18, 634-644.

Osaki, S. \& Johnson, D. A. (1969). Journal of Biological Chemistry 244, 5757-5765.

Owen, C. A. Jr (1973). American Journal of Physiology 224, 514-518.

Pinkerton, P. H., Spence, I., Ogilvie, J. C., Ronald, W. A., Marchant, P. \& Ray, P. K. (1970). Journal of Clinical Pathology 23, 68-76.

Prohaska, J. R. (1981). Nutrition Research 1, 159-167.

Ravin, H. A. (1961). Journal of Laboratory and Clinical Medicine 58, 161-168.

Roeser, H. P., Lee, G. R., Nacht, S. \& Cartwright, G. E. (1970). Journal of Clinical Investigation 49, $2408-2417$.

Smith, S. E. \& Medlicott, M. (1944). American Journal of Physiology 141, 354-358.

Topham, R. W., Woodruff, J. H., Neatrour, G. P., Calisch, M. P., Russo, R. B. \& Jackson, M. R. (1980). Biochemical and Biophysical Research Communications 96, 1532-1539.

Weisenberg, E., Halbreich, A. \& Mager, J. (1980). Biochemical Journal 188, 633-641.

Williams, D. M. Burk, R. F., Jenkinson, S. G. \& Lawrence, R. A. (1981). Journal of Nutrition 111, 979-983.

Williams, D. M., Lee, G. R. \& Cartwright, G. E. (1974). American Journal of Physiology 227, $1094-1097$.

Williams, D. M., Loukopoulos, D., Lee, G. R. \& Cartwright, G. E. (1976). Blood 48, 77-85. 